\title{
Exogenous Glycine Betaine Reduces Drought Damage by Mediating Osmotic Adjustment and Enhancing Antioxidant Defense in Phoebe hunanensis
}

\author{
Yujie Yang ${ }^{1}$, Chengshi Huang ${ }^{2}$, Zuguo Ge ${ }^{3}$, Bengeng Zhou ${ }^{4}$, Guangju Su${ }^{4}$, Chunling Liu ${ }^{4}$ and \\ Yongjun Fei ${ }^{1 \text {,* }}$ \\ ${ }^{1}$ College of Horticulture and Gardening, Yangtze University, Jingzhou, 434025, China \\ ${ }^{2}$ Economics and Management School, Yangtze University, Jingzhou, 434025, China \\ ${ }^{3}$ Chenglong Municipal Garden Design and Research Co. Ltd., Jingzhou, 434020, China \\ ${ }^{4}$ Shuangzhu Forest Farm, Shiyan, 442300, China \\ *Corresponding Author: Yongjun Fei. Email: fyj2010@163.com \\ Received: 18 March 2021 Accepted: 19 May 2021
}

\begin{abstract}
Drought stress negatively impacts growth and physiological processes in plants. The foliar application of glycine betaine (GB) is an effective and low-cost approach to improve the drought tolerance of trees. This study examined the effect of exogenously applied GB on the cell membrane permeability, osmotic adjustment, and antioxidant enzyme activities of Phoebe hunanensis Hand.-Mazz under drought stress. Two levels (0 and $800 \mathrm{~mL})$ of water irrigation were tested under different applied GB concentrations (0,50,100, and $200 \mathrm{mM})$. Drought stress decreased the relative water content by $58.5 \%$ while increased the electric conductivity, malondialdehyde, proline, soluble proteins, soluble sugars, and antioxidant enzyme activities (superoxide dismutase, catalase, peroxidase) by up to $62.9 \%, 42.4 \%, 87.0 \%, 19.1 \%, 60.5 \%, 68.3 \%, 71.7 \%$, and $83.8 \%$, respectively, on the $25^{\text {th }}$ day. The foliar application of GB, especially at $100 \mathrm{mM}$, increased the relative water content of $P$. hunanensis leaves under drought stress. The concentration of GB from 50 to $100 \mathrm{mM}$ effectively alleviated the improvement of cell membrane permeability and inhibited the accumulation of membrane lipid peroxidation products. Under drought stress, the concentrations of proline, soluble proteins, and soluble sugars in the leaves of $P$. hunanensis increased as the applied GB concentration was increased and the water stress time was prolonged. Exogenously applied GB decreased oxidative stress and improved antioxidant enzyme activities as compared with treatments without GB application. Furthermore, the physiological and biochemical indexes of $P$. hunanensis showed a certain dose effect on exogenous GB concentration. These results suggest that GB helps maintain the drought tolerance of $P$. hunanensis.
\end{abstract}

\section{KEYWORDS}

Phoebe hunanensis Hand.-Mazz; drought stress; glycine betaine; osmotic adjustment; antioxidant enzymes activity

\section{Introduction}

Drought stress is a threatening environmental constraint limiting the growth and production of plants in most arid and semiarid regions of worldwide [1]. With global climate change, drought stress is causing increasing concern because of the increasing demand for water for agriculture and forestry and human 
consumption [2,3]. In general, plants differ in drought tolerance. Plants cope with the adverse effects of drought stress through various self-protection and physiological defense mechanisms, such as osmotic adjustment, in vivo antioxidant enzyme regulation, morphological and anatomical changes, and hormonal control [4,5]. Thus, approaches to improve drought tolerance in trees need to be developed urgently. Genetic improvement is a difficult and time-consuming method to increase tree drought tolerance. In addition, its success is limited by the lack of appropriate genes, such as genes conferring tolerance to drought in the germplasm.

Application of biostimulants is a new alternative technique of increasing tree drought tolerance because of their effectiveness, high performance, and low cost [6-8]. Glycine betaine ( $N, N^{\prime \prime}, N^{\prime \prime}$-trimethyl-glycine, GB) is a nitrogenous compound (quaternary amine) that functions in osmotic adjustment and cellular compatibility in plants. Numerous studies analyzed the effect of betaine on different plants under abiotic stress. Wani et al. [9] showed that plants can improve their capacity for osmotic adjustment through inducing betaine accumulation under drought stress. Exogenous foliar application of GB modulates the physiological adaptions in sweet potato under water deficit by accumulating soluble sugars; stabilizing photosynthetic pigments, net photosynthetic rate, and chlorophyll florescence; and improving the overall growth performance [10]. Wang et al. [11] reported that the foliar application of betaine can alleviate drought-induced oxidative damage in plants by stimulating antioxidant enzyme activities and $\mathrm{K}$ uptake; it can also help maintain the stability and integrity of the sub-cellular structure under drought stress. Some studies have reported that foliar application of GB can significantly increase antioxidant enzyme activities under salinity and heavy metal stresses [12-14].

Phoebe hunanensis Hand.-Mazz of the Lauraceae family is mainly distributed in the Yangtze River Basin and the south of the region. P. hunanensis is not only a good timber for premium furniture, carving, and precision mold but also a potential ornamental plant in gardens and landscapes because of its evergreen, tall shape, majestic crown, fast growth, and wind resistance. Previous studies mainly focused on the feeding and dispersal effects of birds on the seeds of P. hunanensis [15] and on seed morphology [16]. However, the drought-betaine interactions in P. hunanensis are largely unknown. Therefore, the present study investigated the effect of exogenous betaine on the cell membrane permeability, osmotic adjustment, and antioxidant enzyme activities of $P$. hunanensis under drought stress.

\section{Materials and Methods}

\subsection{Plant Materials and Treatment}

Two-year healthy and uniform seedlings of P. hunanensis were transferred into plastic pots $(12 \mathrm{~cm}$ deep, $12 \mathrm{~cm}$ in diameter) containing a mixture of substrate $(2: 1: 1$, nutrient soil: vermiculite: sand, $v / v / v)$ in a greenhouse under natural light and $25^{\circ} \mathrm{C} \pm 2{ }^{\circ} \mathrm{C}$ temperature. Plants were irrigated once every 2 days for 30 days. After a pretreatment period of 30 days, two levels of water stress $(0$ and $800 \mathrm{~mL})$ were poured into the soil, and different concentrations of exogenous betaine solution $(0,50,100$, and $200 \mathrm{mM})$ were respectively sprayed to the leaves of $P$. hunanensis for every 3 days lasting for 30 days. A randomized complete block design was employed in the experiment.

The leaves were harvested at $0,5,10,15$, and 25 days after the first treatment through dynamic sampling. The relative water content and electric conductivity were measured with fresh leaves. The other fresh leaves were immediately frozen in liquid nitrogen and stored at $-80^{\circ} \mathrm{C}$ for analyses of proline, malondialdehyde (MDA), soluble sugars and proteins, antioxidant enzyme (superoxide dismutase, SOD; catalase, CAT; and peroxidase, POD) activities. All experiments were performed on three biological replicates.

\subsection{Relative Water Content}

Fresh leaves were cut, and their surface was gently dried. The samples were quickly weighed with a fresh weight $\left(\mathrm{W}_{\mathrm{F}}\right)$ of $0.2 \mathrm{~g}$. The samples were placed in a $50 \mathrm{~mL}$ triangle bottle, added with distilled 
water to the $50 \mathrm{~mL}$ scale line, sealed, and then stored under dark conditions for $24 \mathrm{~h}$. Moisture on the leaf surface was quickly wiped, and the saturated fresh weight $\left(\mathrm{W}_{\mathrm{T}}\right)$ of the samples was weighed. The saturated water-absorbing blade was placed into the aluminum box, de-enzymed at $100^{\circ} \mathrm{C}$ for $15 \mathrm{~min}$, dried at $70^{\circ} \mathrm{C}$ to a constant weight (at least $72 \mathrm{~h}$ ), and then cooled naturally after being taken out. Then, the dry weight $\left(\mathrm{W}_{\mathrm{D}}\right)$ was weighed. The fresh weight, saturated fresh weight, and dry weight obtained from each treatment were used to determine the water status, which is expressed in the form of the percentage leaf water content calculated using the following equation [17]:

Relative water content $(\%)=\frac{W_{F}-W_{D}}{W_{T}-W_{D}} \times 100$

\subsection{Electric Conductivity}

Electric conductivity was determined as described by Feng et al. [18]. The samples were rinsed with double-distilled water and then dried with filter paper. Blade fragments $(0.3 \mathrm{~g})$ were placed in a test tube with a plug and added with $10 \mathrm{~mL}$ of steaming water. After covering the plug, the tubes were allowed to stand for $24 \mathrm{~h}$ at room temperature after full oscillation with an oscillator. A conductivity meter was used to measure electric conductivity. The initial electric conductivity was measured (R1). Then, the beaker was heated in boiling water for $20 \mathrm{~min}$ and cooled. R2 was measured as the final electric conductivity. The electric conductivity of the sample was calculated using the following equation: Electric conductivity $(\%)=\mathrm{R} 1 / \mathrm{R} 2 \times 100$.

\subsection{Proline Contents}

Proline content was determined using the ninhydrin method [19]. Frozen leaf tissue ( $0.2 \mathrm{~g})$ was extracted in $5 \mathrm{~mL}$ of $3 \%(\mathrm{w} / \mathrm{v})$ sulfosalicylic acid at $100^{\circ} \mathrm{C}$ for $10 \mathrm{~min}$ with frequent shaking. After cooling, the extract was filtered into a clean beaker. Then, $2 \mathrm{~mL}$ of the extract was sampled and added to equivalent glacial acetic acid and $3 \mathrm{~mL}$ of $2.5 \%(\mathrm{w} / \mathrm{v})$ ninhydrin. The mixture was then boiled at $100^{\circ} \mathrm{C}$ for $40 \mathrm{~min}$. After cooling, the reaction mixture was extracted with $5 \mathrm{~mL}$ of toluene, the absorbance of the organic phase at $520 \mathrm{~nm}$ was determined, and the content of proline was calculated according to a standard curve. The proline content was calculated using the following formula:

Proline content $=\frac{X \times V_{T}}{W \times V_{S} \times 10^{6}}$,

where $X$ is the measured value $\left(\mu \mathrm{g} \cdot \mathrm{mL}^{-1}\right), V_{T}$ is the extraction liquid volume $(\mathrm{mL}), V_{S}$ is the volume absorbed during measurement $(2 \mathrm{~mL})$, and $W$ is the weighing sample $(\mathrm{g})$.

\subsection{Measurement of MDA Contents}

MDA content was determined using the thiobarbituric acid (TBA) method [20]. Frozen fresh leaves $(0.5 \mathrm{~g})$ were homogenized in $5 \mathrm{~mL}$ of $5 \%(\mathrm{w} / \mathrm{v})$ trichloroacetic acid. The homogenate was centrifuged for $10 \mathrm{~min}$ at $3000 \times \mathrm{g}$. To $2 \mathrm{~mL}$ of the supernatant was added an equal amount of $0.67 \%$ TBA (with 5\% trichloroacetic acid preparation). The reaction solution was held for $30 \mathrm{~min}$ in a boiling water bath, cooled quickly, and then centrifuged at $3000 \times \mathrm{g}$ for $10 \mathrm{~min}$. The absorbance levels of the supernatant were determined at 450,532, and $600 \mathrm{~nm}$. MDA content was calculated using the following formula:

$\operatorname{MDA}\left(\mathrm{mmol} \cdot \mathrm{g}^{-1}\right)=\frac{X \times V_{2} \times V}{M \times V_{1}}$,

where $X$ is the concentration of MDA in the solution to be tested $\left(\mathrm{mmol} \cdot \mathrm{g}^{-1}\right) ; V$ is the total volume of extraction solution $(\mathrm{mL}) ; V_{1}$ is the volume of sample extraction liquid $(\mathrm{mL})$ added in the solution to be tested; and $V_{2}$ is the total volume of the solution to be tested $(\mathrm{mL})$. 


\subsection{Total Soluble Sugars and Total Soluble Proteins}

Anthrone-sulfuric acid colorimetry was used to determine the content of total soluble sugars (TSS) in the leaves [21]. Fresh leaves $(0.3 \mathrm{~g})$ in a test tube with $5 \mathrm{~mL}$ of distilled water were boiled in water for $30 \mathrm{~min}$. Anthrone ethyl $(0.5 \mathrm{~mL})$ and concentrated sulfuric acid $(5 \mathrm{~mL})$ were added into the extracting solution $(0.5 \mathrm{~mL})$. The reaction solution was held for $1 \mathrm{~min}$ in a boiling water bath and free cooled to room temperature for determination at $630 \mathrm{~nm}$. Total soluble protein (TSP) content was measured using the Bradford method [22] with bovine serum albumin as the standard. To prepare extraction, about $0.5 \mathrm{~g}$ of leaf samples was homogenized with $2 \mathrm{~mL}$ of $150 \mathrm{mM}$ buffer solution (containing 0.7 of $\mathrm{NaH}_{2} \mathrm{PO}_{4} \cdot 2 \mathrm{H}_{2} \mathrm{O}$ and $1.64 \% \mathrm{Na}_{2} \mathrm{HPO}_{4} \cdot 12 \mathrm{H}_{2} \mathrm{O}, \mathrm{pH}$ 7.8) subjected to grinding with an ice-cooled mortar and pestle and finally centrifuged at $12,000 \mathrm{rpm}$ for $20 \mathrm{~min}$ at $4{ }^{\circ} \mathrm{C}$. The supernatant was collected for the determination of TSP content.

\subsection{Antioxidant Enzyme Activity}

Frozen leaf tissue $(0.5 \mathrm{~g})$ was homogenized in an appropriate $0.05 \mathrm{M}$ of phosphate buffer $(\mathrm{pH} 7.8)$. The homogenate was filtered through four layers of gauze to remove flesh fragments. The supernatant was centrifuged at $8000 \times \mathrm{g}$ for $10 \mathrm{~min}$ at $4^{\circ} \mathrm{C}$ and then sampled as the crude extract for assays of SOD and POD activities. SOD activity was estimated by recording the decrease in $560 \mathrm{~nm}$ absorbance of nitro-blue tetrazolium dye [23]. POD activity was assayed by Jung et al. [24] using the guaiacol colorimetric method to determine the change in absorbance at $470 \mathrm{~nm}$ wavelength. CAT activity was assayed by monitoring the decomposition of $\mathrm{H}_{2} \mathrm{O}_{2}$ at $240 \mathrm{~nm}$ for $1 \mathrm{~min}$ as previously described by Aebi [25]. The antioxidant enzymes were calculated as follows:

$\operatorname{POD}\left(\mathrm{U} \cdot \mathrm{g}^{-1} \cdot \min ^{-1}\right)=\frac{\Delta A_{470} \times V_{T}}{M \times V_{S} \times 0.01 \times t}$,

where $\Delta A_{470}$ is the change in absorbance at $470 \mathrm{~nm}, V_{T}$ is the total volume (mL) of the enzyme extract, $M$ is the mass of the sample $(\mathrm{g}), V_{S}$ is the volume of the enzyme extraction liquid $(\mathrm{mL})$ used in the determination, and $t$ is the reaction time ( $\mathrm{min})$.

$\operatorname{SOD}\left(\mathrm{U} \cdot \mathrm{g}^{-1} \cdot \min ^{-1}\right)=\frac{\left(A_{C K}-A_{E}\right) \times V_{T}}{A_{C K} \times M \times V_{S} \times 0.5}$,

where $A_{C K}$ is the absorbance value of the illuminated contra-care tube, $A_{E}$ is the absorbance value of the sample, $V_{T}$ is the total volume $(\mathrm{mL})$ of the enzyme extract, $V_{S}$ is the volume $(\mathrm{mL})$ of the enzyme extract used in the measurement, and $M$ is the mass of the sample $(\mathrm{g})$.

$\operatorname{CAT}\left(\mathrm{U} \cdot \mathrm{g}^{-1} \cdot \min ^{-1}\right)=\frac{\Delta \mathrm{A}_{240} \times \mathrm{Vt}}{0.1 \times \mathrm{V}_{1} \times t \times \mathrm{FW}}$

where $\Delta \mathrm{A}_{240}=\mathrm{A}_{\mathrm{S} 0^{-}}\left(\mathrm{A}_{\mathrm{S} 1}+\mathrm{A}_{\mathrm{S} 2}\right) / 2, \mathrm{~A}_{\mathrm{S} 0}$ is the absorbance value of the tube after adding the boiled enzyme solution, $A_{S 1}, A_{S 2}$ is the absorbance value of the sample tube, $V_{T}$ is the total volume of the crude enzyme extract $(\mathrm{mL}), \mathrm{V}_{1}$ is the volume of the crude enzyme liquid used for determination $(\mathrm{mL})$, and $\mathrm{FW}$ is the fresh weight of the sample (g). $\Delta \mathrm{A}_{240}$ means that each 0.1 drop is 1 enzyme activity unit (U), and $t$ is the period from adding hydrogen peroxide to the last reading time (min).

\subsection{Statistical Analysis}

Data were reported as mean \pm SD for triplicate determinations along with standard errors of means. Data were further subjected to analysis of variance, and mean differences were compared using Duncan test (SPSS19.0). Statistical significance was declared at $p<0.05$. All indexes were evaluated with drought resistance by using the subordinative function value method. The subordinative function value was 
calculated using the following formula:

$Z_{i j}=\frac{X_{\mathrm{ij}}-X_{\mathrm{imin}}}{X_{i \max }-X_{i \min }}$.

If the index is negatively correlated with drought resistance,

$Z_{i j}=1-\frac{X_{\mathrm{ij}}-X_{\mathrm{imin}}}{X_{i \max }-X_{i \min }}$

\section{Results}

\subsection{Changes in Relative Water Content}

The effects of different GB concentrations on the relative water content in P. hunanensis are shown in Fig. 1. Water displayed a great effect on relative water content. Compared with that under $800 \mathrm{~mL}$ water irrigation, the relative water content under drought stress $(0 \mathrm{~mL}$ water $)$ decreased by $58.5 \%$ without GB on day 25 (Tab. S1). As shown in Fig. 1A, when $0 \mathrm{~mL}$ water was irrigated, the relative water content of $P$. hunanensis leaves gradually decreased with the extension of drought stress time. The highest value was obtained with $100 \mathrm{mM} \mathrm{GB}$ (G100); it was significantly higher than the other values obtained, except at 0 and 5 days of treatment at $0 \mathrm{~mL}$ water irrigation $(p<0.05$, Fig. 1A). As displayed in Fig. 1B, when $800 \mathrm{~mL}$ water was irrigated, the highest content of relative water was achieved after G50 treatment from day 5 to day 25. However, as time was prolonged, the relative water content of $P$. hunanensis leaves decreased under the influence of GB. Thus, under the condition of full irrigation, the relative water content of $P$. hunanensis leaves decreased with the increase in GB concentration. The higher the GB concentration is, the more obvious the trend of relative water content decrease.
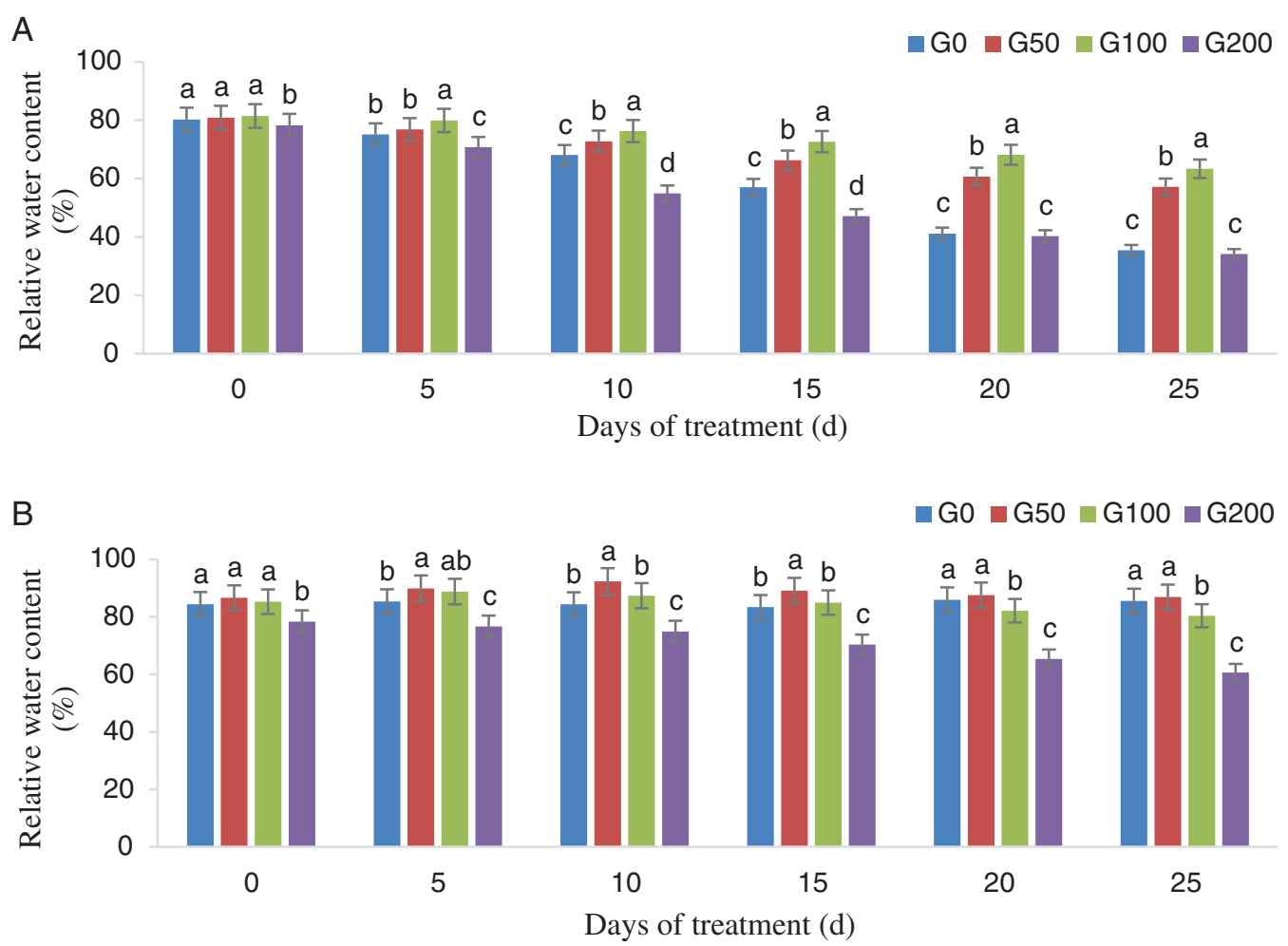

Figure 1: Effects of different GB concentrations on the relative water content of Phoebe hunanensis leaves. $\mathrm{A}$ and $\mathrm{B}$ represent two degrees of water stress 0 and $800 \mathrm{~mL}$. Each value represents the mean of three replicates of each plant, and the different normal letters in the same columns indicate significant differences at $p<0.05$ 
With the application of $200 \mathrm{mM}$ GB (G200), the relative water content was lower than all other treatments under both irrigation conditions. Furthermore, with the intensification of drought, the effective concentration of GB increased gradually. Therefore, the application of low- and medium-concentration GB solutions can effectively maintain the water content of $P$. hunanensis leaves, whereas highconcentration GB will cause a certain degree of damage to the leaves.

\subsection{Changes in Electric Conductivity}

Conductivity is an important indicator to reflect cell membrane permeability. The higher the cell tissue conductivity is, the greater the cell membrane permeability and the greater the damage to cell membrane integrity will be. As shown in Fig. 2A, the relative electrical conductivity of P. hunanensis (G0) leaves increased with the extension of drought stress time when $0 \mathrm{mM}$ GB solution (G0) was applied as the control group and $0 \mathrm{~mL}$ water was irrigated. Without $\mathrm{GB}(\mathrm{G} 0)$, the electric conductivity of drought stress $(0 \mathrm{~mL}$ water irrigation) was higher than $800 \mathrm{~mL}$ water irrigation by $62.9 \%$ (Tab. S1). The concentration of GB at $200 \mathrm{mM}(\mathrm{G} 200)$ was significantly higher than that of the other groups $(p<0.05)$ from day 0 to day 15 . On day 10 , the relative conductivity of $P$. hunanensis leaves treated with G50 and G100 was significantly lower than those of the control group and G200 $(p<0.05)$, and the effect of G100 was better than that of G50. Therefore, GB at low and medium concentrations could reduce the electrolyte permeability of $P$. hunanensis leaves and stabilize their cell membrane structure. High concentrations of GB initially caused damage to leaf membrane structures, but the damage was self-repairing to some extent.
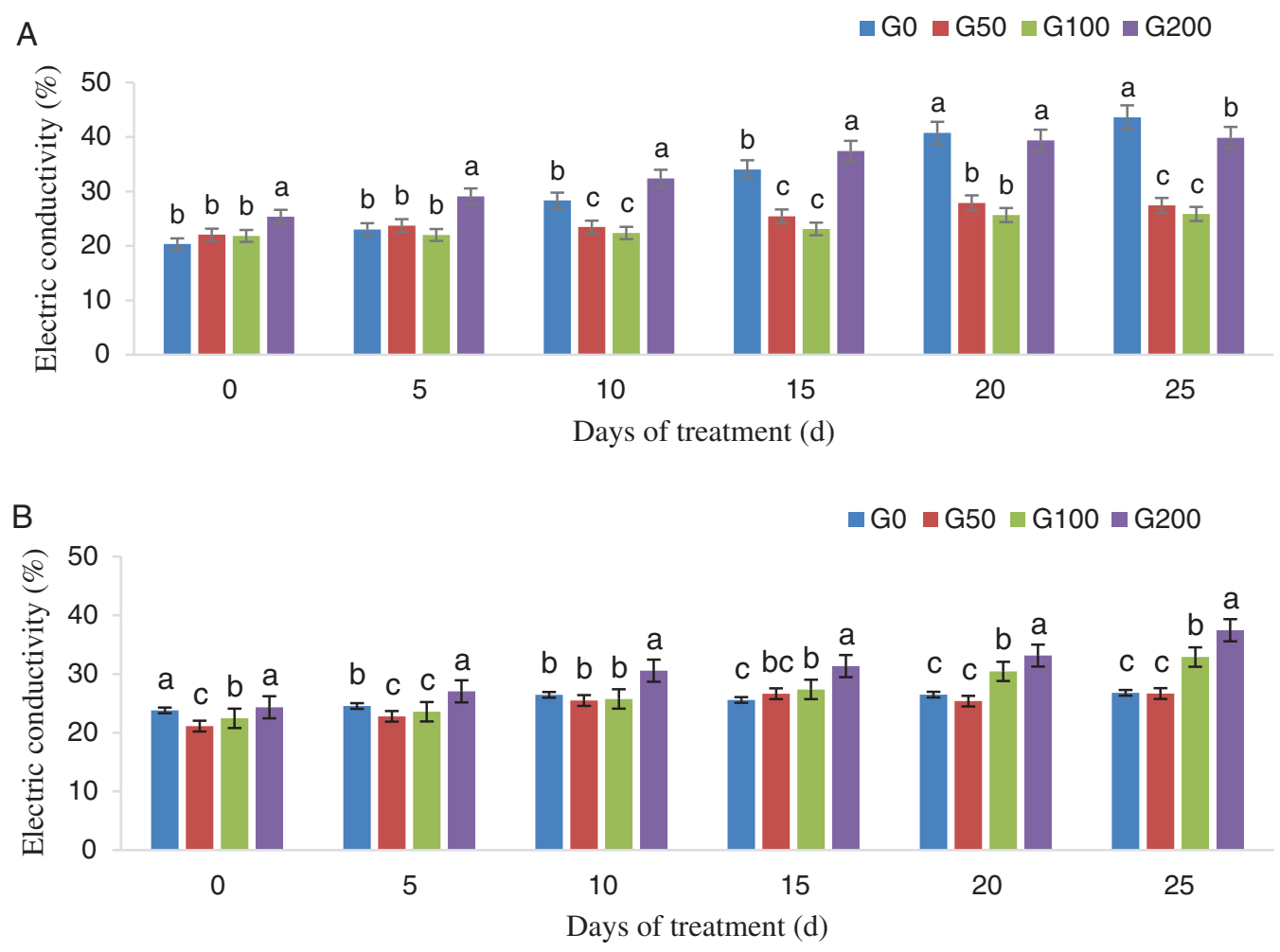

Figure 2: Effects of different GB concentrations on the electric conductivity of leaves of Phoebe hunanensis. A and B represent two degrees of water stress 0 and $800 \mathrm{~mL}$. Each value represents the mean of three replicates of each plant, and the different normal letters in the same columns indicate significant differences at $p<0.05$ 
As shown in Fig. 2B, when $800 \mathrm{~mL}$ water was poured, the relative conductivity of leaves in the control group remained unchanged. The relative electrical conductivity of G50 and G100 leaves was significantly lower than that of the control group from day 0 to day $5(p<0.05)$. After 5 days, the relative conductivity of the G50 leaves was basically at the same level as that of the G0 leaves. After 15 days, the relative conductivity of the G100 leaves gradually increased, which was significantly higher than that of the control group $(p<0.05)$. The relative conductivity of G200 leaves was always higher than that of the control group.

\subsection{Changes in MDA Content}

MDA, which is the final decomposition product of lipid peroxidation due to oxidative stress, is also an indicator of membrane damage. As shown in Fig. 3A, when $0 \mathrm{mM} \mathrm{GB}(\mathrm{G} 0)$ was sprayed as the control group and $0 \mathrm{~mL}$ water was irrigated, the MDA content in the leaves of $P$. hunanensis $\mathrm{G} 0$ gradually increased with the extension of drought stress time, which was higher than that under $800 \mathrm{~mL}$ water irrigation (G0) by $42.4 \%$ on day 25 (Fig. 3B, Tab. S1). A high concentration of GB can significantly increase MDA content in the leaves $(p<0.05)$, whereas a low concentration of GB was sprayed on the leaves to reduce MDA content significantly $(p<0.05)$. From day 0 to day 5, MDA at $100 \mathrm{mM}$ GB (G100) in the leaves was higher than that in the control group. After 15 days, MDA at G100 in the leaves was significantly lower than that in the control group $(p<0.05)$. The treatment of medium-concentration GB was not initially very sensitive to the drought stress in $P$. hunanensis, and G50 exerted the most significant effect on drought stress in P. hunanensis.
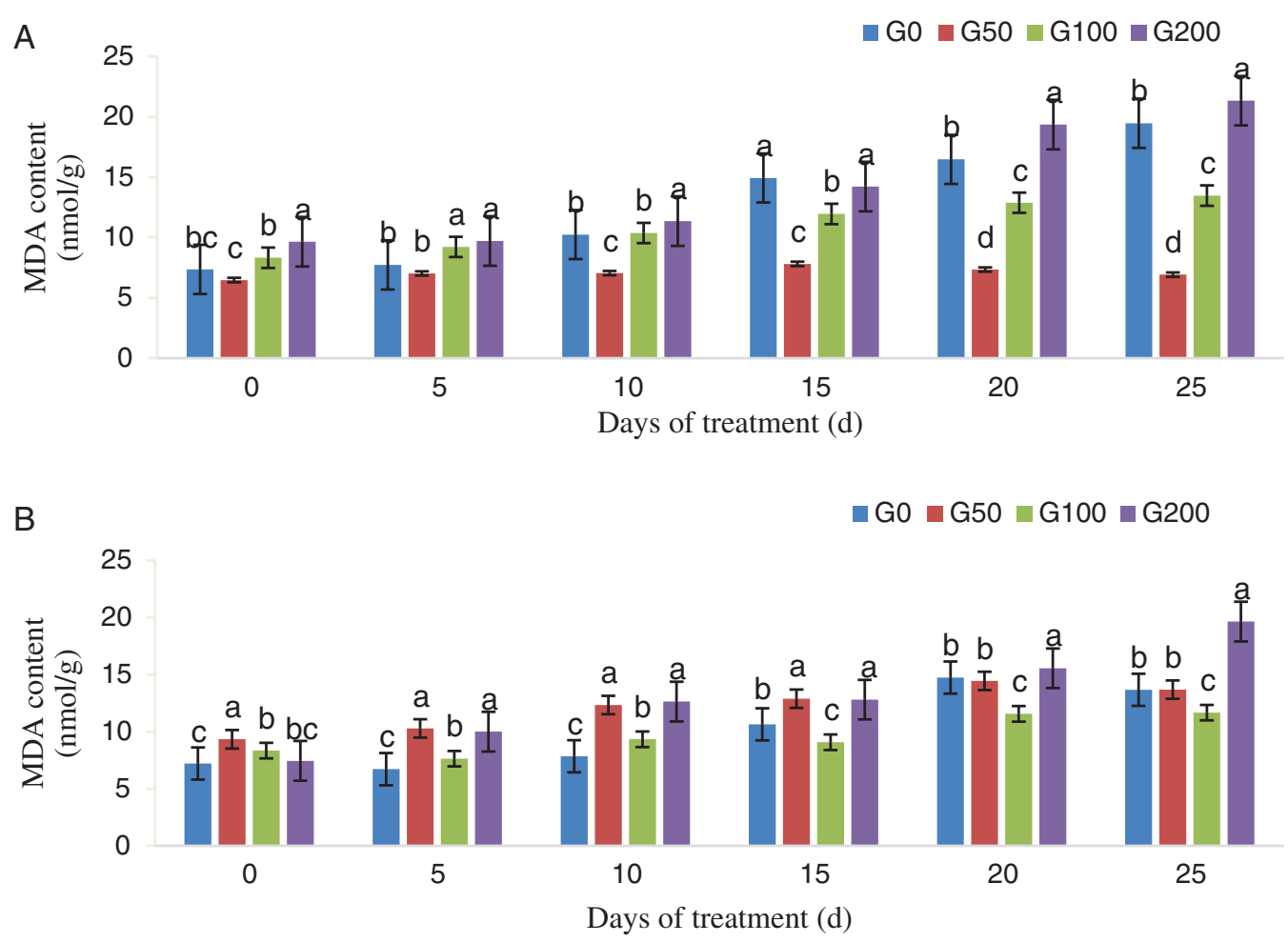

Figure 3: Effects of different GB concentrations on the malondialdehyde content of leaves of Phoebe hunanensis. A and B represent two degrees of water stress 0 and $800 \mathrm{~mL}$. Each value represents the mean of three replicates of each plant, and the different normal letters in the same columns indicate significant differences at $p<0.05$ 
When $800 \mathrm{~mL}$ water was poured from day 0 to day 10 , the MDA content in the leaves sprayed with GB was significantly higher than that in the control group ( $p<0.05$, Fig. 3B). After 10 days, the MDA content in the G100 leaves was significantly lower than that in the control group $(p<0.05$, Fig. 3B). The MDA content in the G200 leaves was significantly higher than that in the control group ( $p<0.05$, Fig. 3B), and that in the G50 leaves was at the same level as that in the control group.

\subsection{Changes in Proline Content}

Proline is an important osmotic regulator in plants, and an increase in its content is strongly related to the degree of damage to plants. Under drought stress $(0 \mathrm{~mL}$ water irrigation), the proline content in $P$. hunanensis leaves was greater than that with $800 \mathrm{~mL}$ water irrigation under $\mathrm{G} 0$ conditions; in specific, it was higher by $87.0 \%$ on day 25 (Tab. S1). When $0 \mathrm{mM} \mathrm{GB}(\mathrm{G} 0)$ was sprayed as the control group, the proline content in $P$. hunanensis leaves gradually increased with the extension of drought time (Fig. 4A). The proline content in the leaves of the GB treatment group was significantly higher than that of the control group $(p<0.05)$, and the proline content gradually increased with the increase in GB concentration. Thus, GB can promote the accumulation of proline in the leaves of $P$. hunanensis under drought conditions, and it increases with the increase in GB concentration.
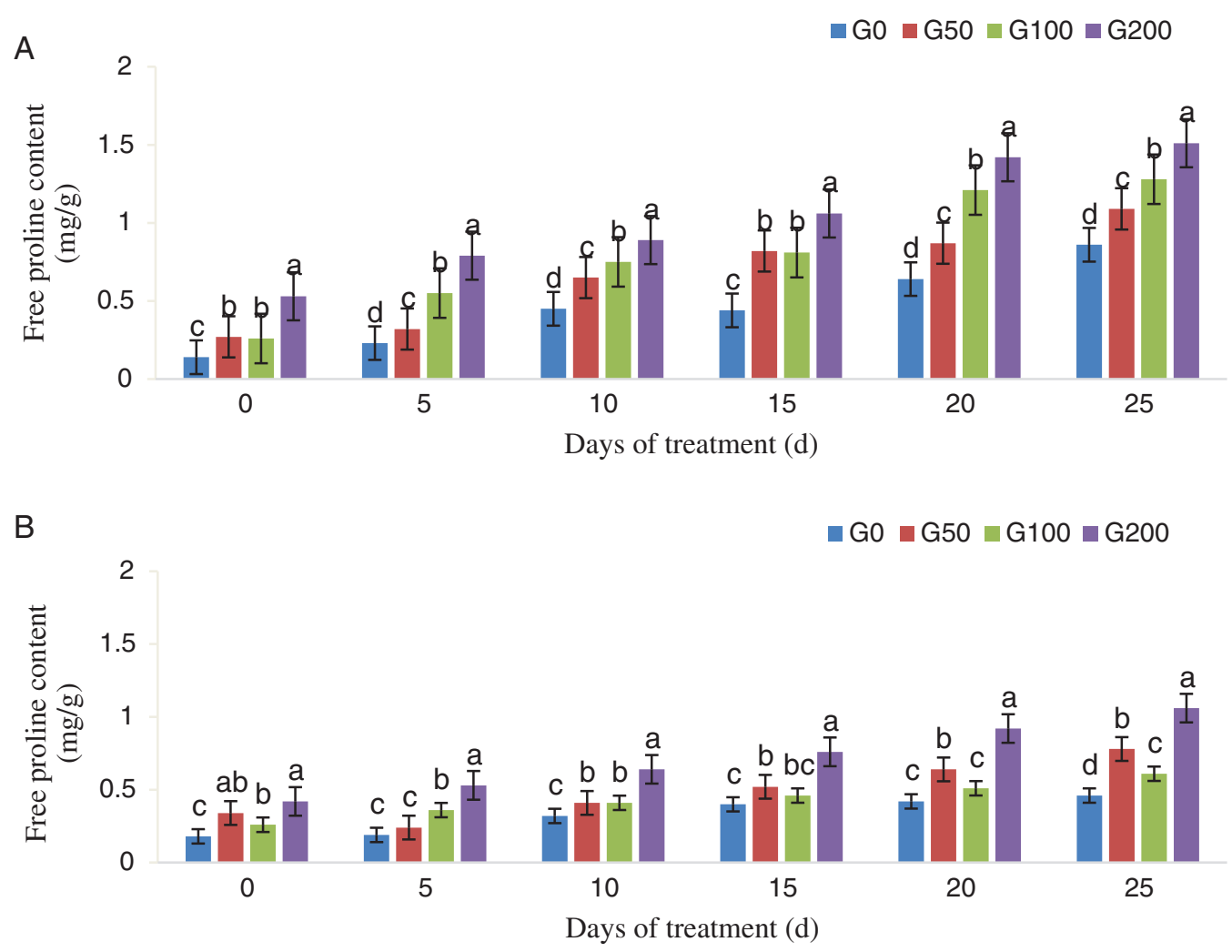

Figure 4: Effects of different GB concentrations on the free proline content of Phoebe hunanensis leaves. $\mathrm{A}$ and $\mathrm{B}$ represent two degrees of water stress 0 and $800 \mathrm{~mL}$. Each value represents the mean of three replicates of each plant, and the different normal letters in the same columns indicate significant differences at $p<0.05$ 
When $800 \mathrm{~mL}$ water was poured, the proline content in the leaves of $P$. hunanensis can be increased by spraying GB (Fig. 4B). The proline content in the G200 and G50 leaves was significantly higher than that in the control group $(p<0.05$, Fig. 4B). The proline content in the leaves under the treatment of G100 was also higher than that of the control group but significantly lower than that of G200 and G50. These results showed that the increase in proline content of $P$. hunanensis leaves was reduced when the GB concentration was $100 \mathrm{mM}$ than when it was 50 and $200 \mathrm{mM} \mathrm{GB}$.

\subsection{Changes in Soluble Proteins}

With regard soluble proteins, the seedlings of $P$. hunanensis under drought stress were higher than that at adequate irrigation by $19.1 \%$ (Tab. S1). When $0 \mathrm{mM} \mathrm{GB}(\mathrm{G} 0)$ was sprayed, the soluble protein content of $P$. hunanensis leaves gradually increased with the extension of drought time (Fig. 5A). The soluble protein content in the leaves of the GB treatment group was significantly higher than that of the control group ( $p<0.05$, Fig. 5A). In addition, the soluble protein content gradually increased with the increase in GB concentration. Hence, GB could promote the synthesis of soluble proteins in the leaves of $P$. hunanensis under drought stress, and it was positively correlated with GB concentration.
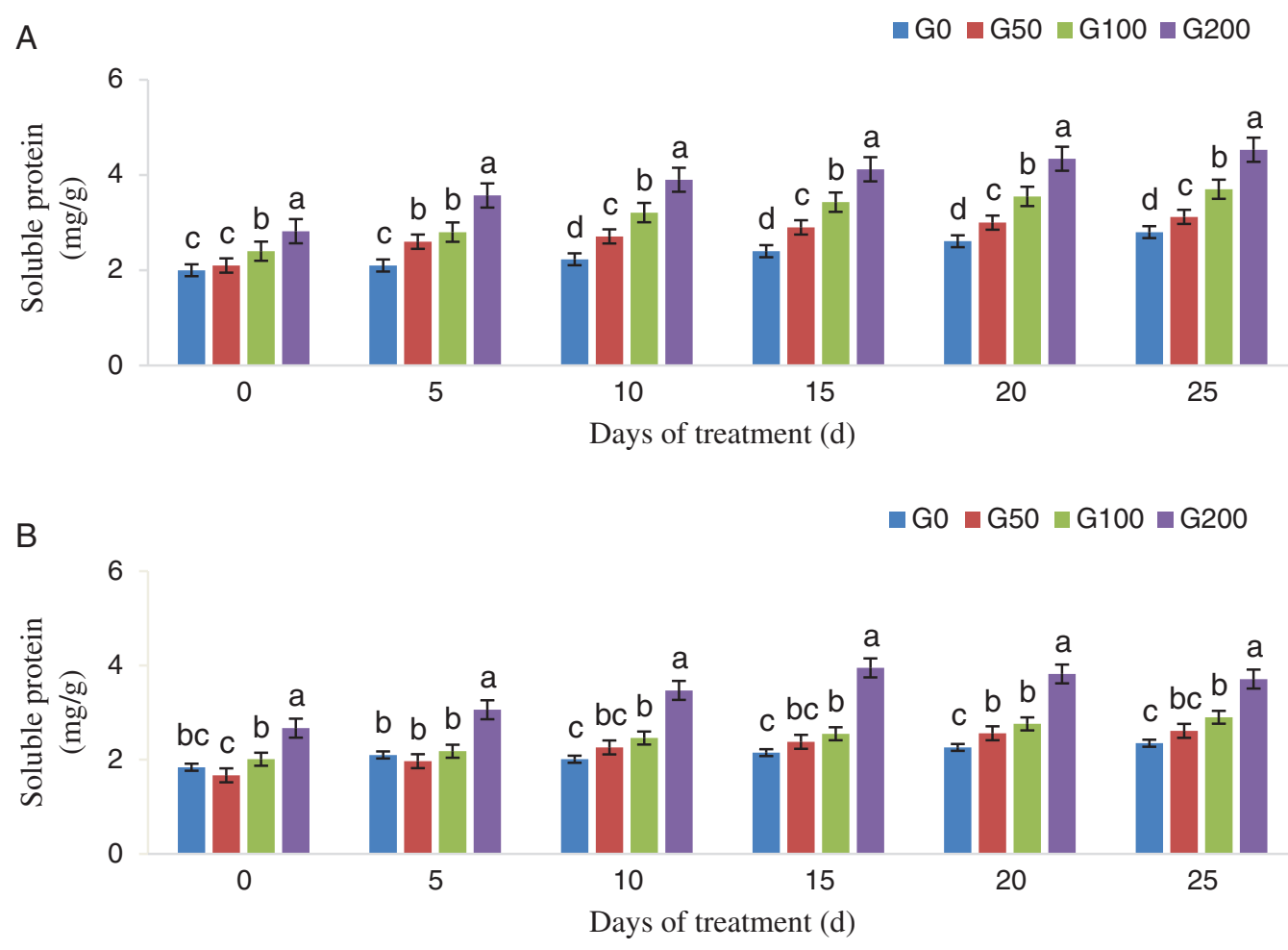

Figure 5: Effects of different GB concentrations on the soluble protein content of Phoebe hunanensis leaves. A and B represent two degrees of water stress 0 and $800 \mathrm{~mL}$. Each value represents the mean of three replicates of each plant, and the different normal letters in the same columns indicate significant differences at $p<0.05$

The soluble protein content of $P$. hunanensis leaves was basically maintained at the same level when $800 \mathrm{~mL}$ water was poured without GB (Fig. 5B). From day 0 to day 5, the soluble protein content of the G50 leaves was lower than that of the control group; on day 5, the soluble protein content of the G50 leaves was higher than that of the control group, and no significant differences were found in the soluble protein contents of G50 and G100 ( $p>0.05$, Fig. 5B). 


\subsection{Changes in Total Soluble Sugars}

The soluble sugar content of $P$. hunanensis leaves increased with the extension of drought time when $0 \mathrm{~mL}$ water was irrigated (Fig. 6A), whereas the soluble sugar content almost remained unchanged when $800 \mathrm{~mL}$ water was irrigated (Fig. 6B). On day 25, compared with regulation irrigation, drought stress increased total soluble sugar content by $60.5 \%$ (Tab. S1). On day 0 to day 10 , no significant difference in soluble sugar content was found among G100, G50, and G0 $(p>0.05)$. The soluble content of the G200 leaves was always significantly higher than that of the G0 leaves $(p<0.05)$. Thus, under drought conditions, high-concentration GB could significantly increase the soluble sugar content in $P$. hunanensis leaves, whereas low- and medium-concentration GB could also accumulate the soluble sugars in $P$. hunanensis leaves under drought stress.
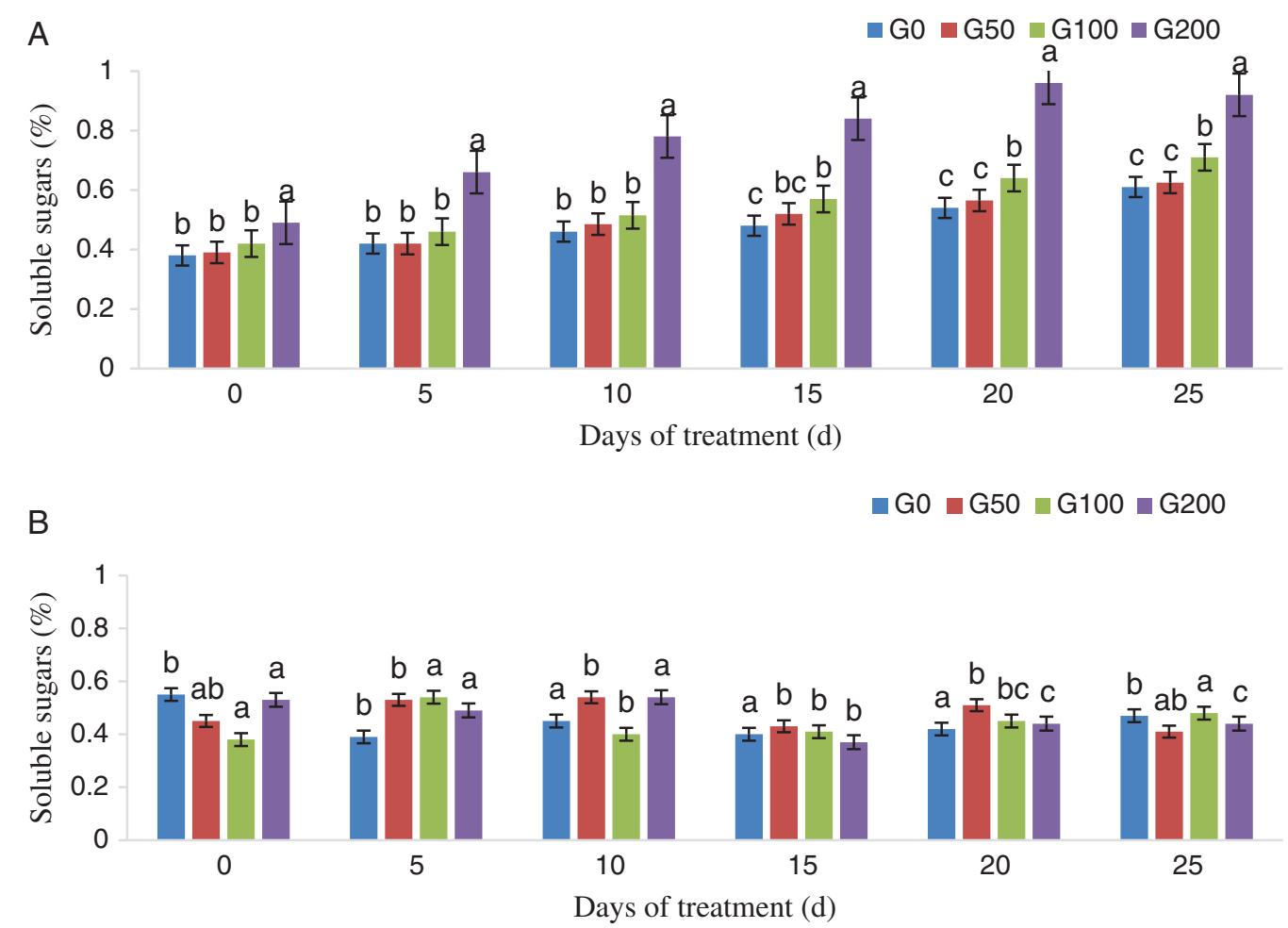

Figure 6: Effects of different GB concentrations o on the soluble sugar content of Phoebe hunanensis leaves. A and B represent two degrees of water stress 0 and $800 \mathrm{~mL}$. Each value represents the mean of three replicates of each plant, and the different normal letters in the same columns indicate significant differences at $p<0.05$

As shown in Fig. 6B, after being irrigated with $800 \mathrm{~mL}$ water for 15 days, $\mathrm{GB}$ was sprayed to reduce the soluble sugar content of $P$. hunanensis leaves, especially at the G100 treatment, which was significantly lower than that of the control group $(\mathrm{G} 0)(p<0.05)$. The soluble sugar content of the G50 leaves was higher than that of the control group from day 0 to day 10 but lower than that of the control group after day 15. After day 10, the soluble sugar content of the G200 leaves was lower than that of the control group.

\subsection{Changes in Antioxidant Enzyme Activity}

\subsubsection{Changes in Superoxide Dismutase Activity}

Compared with normal irrigation ( $800 \mathrm{~mL}$ water irrigation), the SOD activity under drought stress (G0) was higher by $15.9 \%, 6.8 \%, 5.5 \%, 26.4 \%, 63.9 \%$, and $68.3 \%$ on days $0,5,10,15,20$, and 25 (Tab. S1). 
The SOD activity in the leaves of the control group increased with the extension of drought time when $0 \mathrm{~mL}$ water was irrigated (Fig. 7A). No significant difference in SOD activity was found between the G50 leaves and the control group $(p>0.05)$, indicating that the low concentration of GB under drought stress exerted no effect on the SOD activity in P. hunanensis leaves. The SOD activity of the G200 leaves was higher than that of the control group (G0) in the early stage of drought stress but decreased gradually in the middle and late stages and was lower than that of the control group. The SOD activity of the G100 leaves was significantly higher than that of the control group $(p<0.05)$, which showed that the medium concentration of GB can enhance SOD activity in $P$. hunanensis leaves.
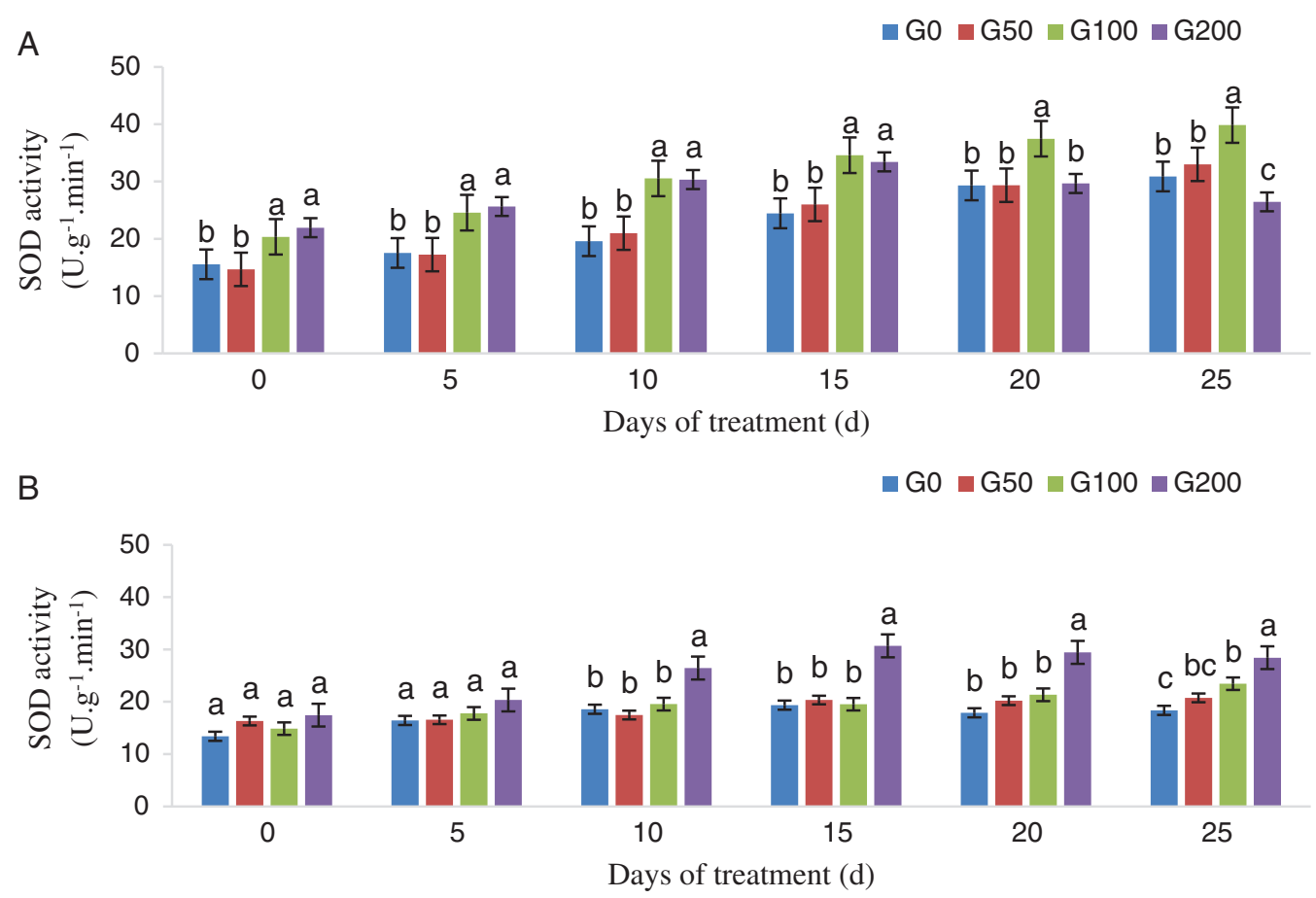

Figure 7: Effects of different GB concentrations on the superoxide dismutase activity of Phoebe hunanensis leaves. A and B represent two degrees of water stress 0 and $800 \mathrm{~mL}$. Each value represents the mean of three replicates of each plant, and the different normal letters in the same columns indicate significant differences at $p<0.05$

The SOD activity in the leaves sprayed with GB at different concentrations was basically at the same level as that of the control group on day 0 to day 5 when $800 \mathrm{~mL}$ water was irrigated $(p<0.05$, Fig. $7 \mathrm{~B})$. After 10 days, the SOD activity of the G200 leaves was significantly higher than that of the leaves in the three other groups $(p<0.05)$. Therefore, when $800 \mathrm{~mL}$ water is irrigated, spraying low- and mediumconcentration GB can only slightly enhance SOD activity in $P$. hunanensis leaves, whereas spraying highconcentration GB can enhance SOD activity in $P$. hunanensis leaves.

\subsubsection{Changes in Catalase Activity}

As shown in Tab. S1, the CAT activity under drought stress was greater by $71.7 \%$ than that of $800 \mathrm{~mL}$ water irrigation on day 25 without GB on P. hunanensis. The CAT activity in the leaves increased with the extension of drought time when $0 \mathrm{~mL}$ water was poured (Fig. 8A). Under drought stress, different GB concentrations were sprayed to significantly increase CAT enzyme activity ( $p<0.05$, Fig. 8A), especially at G100 treatment. The CAT activity in the G200 leaves initially increased and then decreased, which was 
always higher than that of the control group. Therefore, $P$. hunanensis leaves could cope with the adverse environment by improving CAT activity under drought stress, and the suitable concentration of GB could further improve the CAT activity in the leaves. When $800 \mathrm{~mL}$ water was irrigated, the CAT activity in P. hunanensis leaves gradually increased with the extension of time (Fig. 8B). The CAT activity in the leaves of GB treatment was stronger than that of the control group. With the increase in GB concentration, the CAT activity in the leaves gradually increased. Therefore, under the irrigation of $800 \mathrm{~mL}$ water, GB could improve the CAT activity in $P$. hunanensis leaves in a concentrationdependent manner.

A -G0 $\approx \mathrm{G} 50=\mathrm{G} 100=\mathrm{G} 200$

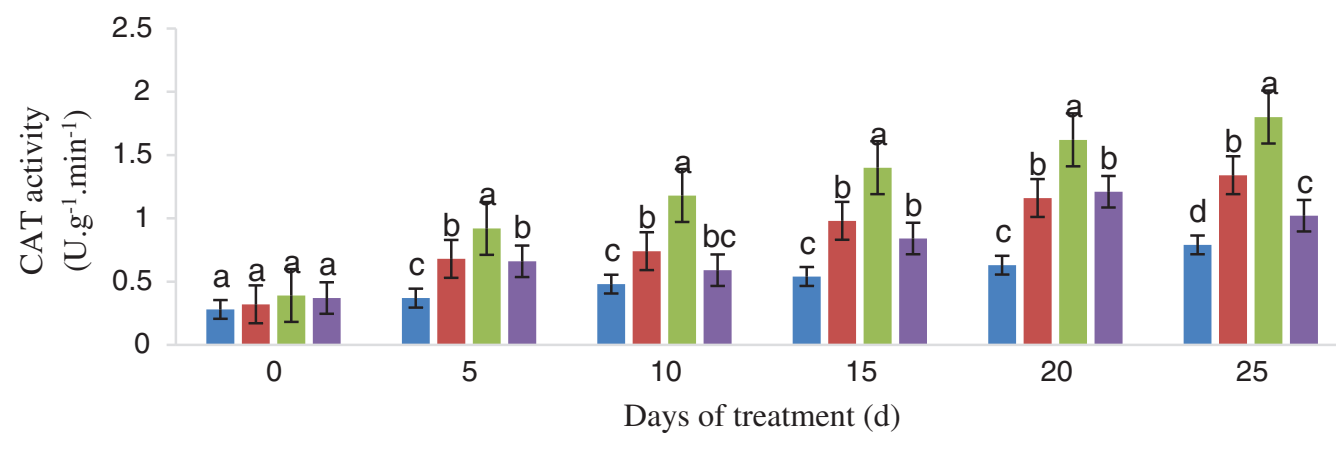

B

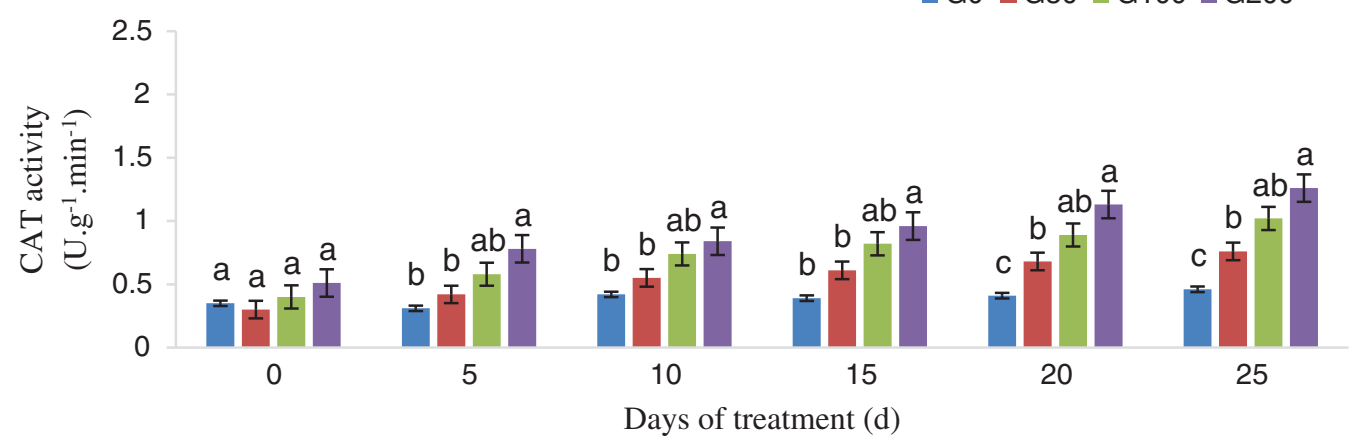

Figure 8: Effects of different GB concentrations on the catalase activity of Phoebe hunanensis leaves. A and $B$ represent two degrees of water stress $0,800 \mathrm{~mL}$. Each value represents the mean of three replicates of each plant, and the different normal letters in the same columns indicate significant differences at $p<0.05$

\subsubsection{Changes in Peroxidase Activity}

Compared with $800 \mathrm{~mL}$ water irrigation, the $P$. hunanensis seedlings under drought stress $(0 \mathrm{~mL}$ water irrigation) increased POD activity by $44.5 \%, 46.8 \%$, and $83.8 \%$ from day 15 to day 25 (Tab. S1). As shown in Fig. 9A, no significant difference in leaf POD activity was found between the control group (G0) and application of GB at different concentrations $(p>0.05)$. After 10 days, the POD activity of the G200 leaves was significantly higher than that of the control group $(p<0.05)$, and the POD enzyme activity of the G50 leaves was lower than that of the control group. Under drought stress, lowconcentration betaine solution can reduce the POD activity in $P$. hunanensis leaves, whereas highconcentration betaine solution can improve the POD activity in P. hunanensis leaves. With the extension of time, the POD activity in the leaves gradually increased (Fig. 9B). Compared with the control group, 
the increase in POD activity in $P$. hunanensis leaves after spraying GB was greater than that after irrigation with $800 \mathrm{~mL}$ water. Thus, GB could improve the POD activity in $P$. hunanensis leaves.
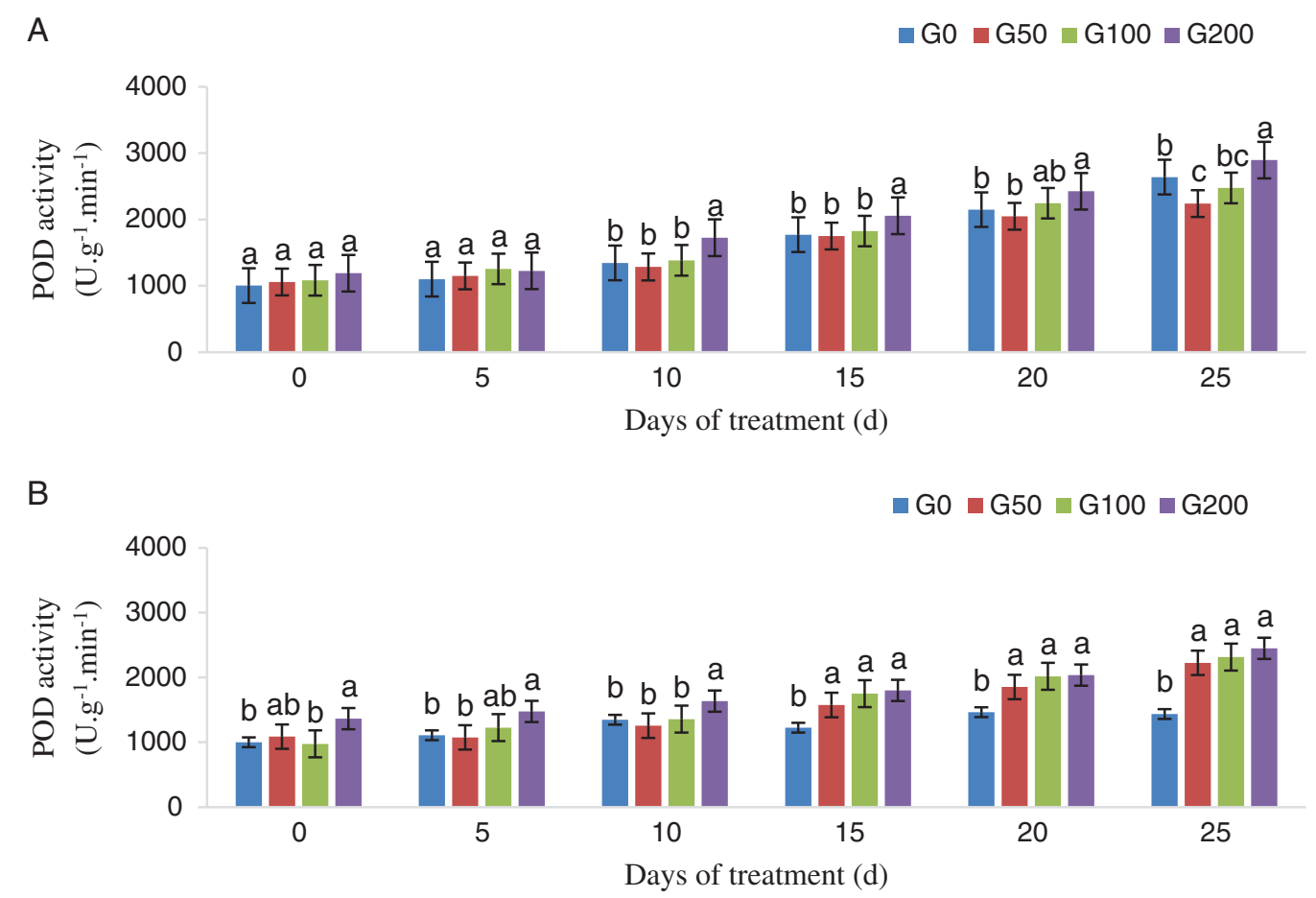

Figure 9: Effects of different GB concentrations on the peroxidase activity of Phoebe hunanensis leaves. $\mathrm{A}$ and $\mathrm{B}$ represent two degrees of water stress 0 and $800 \mathrm{~mL}$. Each value represents the mean of three replicates of each plant, and the different normal letters in the same columns indicate significant differences at $p<0.05$

\section{Discussion}

\subsection{Effects of Exogenous GB on the Physiological Effects in P. hunanensis Leaves}

Drought breaks the water balance in plants first, thus affecting the normal physiological and biochemical functions of plants. Relative water content is an index of water potential in plants, which can directly reflect the water content and dehydration degree of plants. Therefore, it can be used as an indicator of plant damage under stress [26]. In the present study, spraying GB alleviated the decreasing trend of relative water content of $P$. hunanensis leaves under drought stress, which was consistent with the research of Shemi et al. [27] on Zea mays. Results showed that GB can effectively delay leaf wilting, repair leaf damage, and improve its drought resistance. The effect of GB on retarding leaf wilting was inhibited during gradually watering. Under sufficient irrigation conditions, the relative water content of $P$. hunanensis leaves could not be maintained by spraying GB, whereas the relative water content of $P$. hunanensis leaves could be reduced by high concentrations of GB solution. Genard et al. [28] reported that GB not only maintains plant water in arid environment, which may be due to its strong hydrophilicity and solubility, and also plays a role of osmotic protection of plant tissues. The leaves and roots of plants absorbed the exogenous GB sprayed and stored it in the plant body through accumulation, thereby reducing the osmotic potential of plant cells and reducing the water loss in the cells under stress. Alasvandyari et al. [29] showed that GB can promote the $\mathrm{Na}^{+}$excretion and $\mathrm{K}^{+}$accumulation of plants under drought stress and improve the osmotic regulation ability of plants by improving ion balance to maintain the water content of plant leaves. 
Under abiotic stresses, the accumulation of free radicals in plants can damage cell membranes. Leaf conductivity often represents the stability of cell membrane, and MDA is the product of lipid peroxidation, both of which are important indicators of cell membrane damage [4]. In the present study, the relative electrical conductivity and MDA content in the leaves of $P$. hunanensis in the control group significantly increased under drought stress, and the stability of the cell membrane reduced, which was consistent with the results of Nawaz et al. [30] on Axonopus compressus and Nazar et al. [31] on Carthamus tinctorius. Spraying low-concentration GB effectively restrained the P. hunanensis leaf conductivity and increased MDA content, which indicated that a suitable concentration of GB could reduce cell membrane damage, decelerate membrane lipid peroxidation, maintain the normal structure and function of the cell membrane, and help repair the damage to $P$. hunanensis under drought stress. However, under adequate irrigation, GB spray may damage the cell membrane structure of $P$. hunanensis leaves and improve the electrolyte permeability with time extension. The higher the concentration of GB, the more destructive it will be. These results showed that GB could not only affect the electrical conductivity and MDA content of $P$. hunanensis leaves under stress but also exert diverse effects at different concentrations.

\subsection{Effects of Exogenous GB on the Osmotic Regulation System in P. hunanensis Leaves}

Plants under environmental stress accumulate osmotic regulators, which help reduce cell osmotic potential, maintain cell expansion pressure, and improve the water absorption ability of cells. The decrease in osmotic potential caused by the increase in intracellular solute is osmotic regulation and an important way for plants to protect themselves under stress [32]. Numerous researches reported that drought stress induces the accumulation of osmotic substances, such as proline [33], soluble proteins [34], and soluble sugars [35], in plants to improve drought resistance. In the present study, with the extension of drought stress time, the contents of proline, soluble proteins, and soluble sugars in the leaves of $P$. hunanensis all increased, indicating that the contents of free proline, soluble proteins, and soluble sugars could be increased in $P$. hunanensis leaves to maintain osmotic balance. Compared with the control group, GB dose-dependently increased the contents of free proline and soluble proteins in P. hunanensis leaves.

The research of Mattioni et al. [36] on hard wheat explained how exogenous GB application increases proline content. The accumulation of proline mainly through the excitation and inhibition of oxidative and protein synthesis blocked the combination of three aspects, and the synthesis of proline was the main way of accumulation. Thus, we speculated that exogenous GB could affect more than one or several links to increase the accumulation of proline under drought stress. The study on P. hunanensis in this experiment found that proline would not accumulate in plants under full irrigation, and spraying exogenous GB would not affect the proline content. In addition, GB works only under drought stress. Therefore, we speculated that the synthesis of proline is signaling through water stress, and exogenous GB participates in the signal transduction pathway, accelerates or amplifies signal transduction as a molecular chaperone, or directly stimulates the synthesis of proline as a signal molecule. Wang [37] found that exogenous GB is inhibited by inducing the overexpression of drought-related genes or degradation pathways, thus improving the drought tolerance of apple.

Soluble proteins are important osmotic regulators and nutrients in plants; they protect cell biological macromolecules, improve the water retention of cells, and serve as important indexes for resistance screening [38]. In the present study, exogenous GB increased the soluble protein content of $P$. hunanensis leaves under drought stress, which is consistent with the research results of Raza et al. [39]. Thus, exogenous GB could not only inhibit the water loss of cells but also alleviate the damage of drought to the structure and function of biological macromolecules (enzymes and proteins, etc.) in cells. However, the mechanism by which GB affects soluble proteins remains unclear. Bourot et al. [40] suggested that 
$\mathrm{GB}$, as an opaque substance, could help proteins refold after denaturation and stabilize proteins under adverse conditions. By contrast, Iqbal et al. [41] believed that GB provides the right conditions for protein accumulation by improving the water status of plants. We speculate that GB may be involved in the synthesis of stress-stable proteins to alleviate the inhibition of drought on protein synthesis or to prevent protein degradation under stress so that protein synthesis is still greater than decomposition, thus increasing the soluble protein content of $P$. hunanensis.

\subsection{Effects of Exogenous GB on Antioxidant System in P. hunanensis Leaves}

Numerous studies $[29,42,43]$ have shown that under normal conditions, the production and removal of reactive oxygen species (ROS) in plants maintain a balance, and net accumulation of ROS does not occur in cells. Under drought stress, ROS production breaks the balance of the ROS scavenging system, which leads to oxidative damage, such as membrane lipid peroxidation. SOD, CAT, and POD are the key enzymes in the antioxidant system of plants. They not only eliminate excessive ROS and prevent the formation of free radicals in plants but also improve plant stress resistance by reasonably regulating the antioxidant system and play an important role in coping with drought and other stresses $[9,44,45]$. A large number of experiments have also confirmed the theory that GB improves the activity of antioxidant enzymes and antioxidant substances in plants under stress. The results of this experiment showed that under drought stress, the application of GB significantly increased the activity of antioxidant enzymes compared with the control group, among which the most obvious promotion effect was on the activity of CAT, and the treatment effect was the best when the GB concentration was $100 \mathrm{mM}$. These results indicated that GB could enhance the drought resistance of $P$. hunanensis. In addition, under sufficient irrigation conditions, although GB treatment could also enhance the activity of antioxidant enzymes, it was not related to the concentration of GB.

Several studies explored the mechanism by which GB improves the antioxidant defense system of plants [46-50]. At present, whether or not GB can directly act on the antioxidant system and by what means or how it affects the expression of relevant genes remain to be further explored and studied.

\subsection{Dose Effect of Exogenous GB}

At present, studies on the dose effect of GB are very limited. The best concentrations of GB were screened out from apple [51], rice [52], cotton [53], and ryegrass [54,55] under adverse environmental stress conditions. In our study, the effects of different concentrations of GB on the physiological and biochemical indexes of $P$. hunanensis leaves were also different, and the treatment with high GB concentration may exert an inhibitory effect and achieve the opposite effect. Therefore, to find the most suitable concentration can effectively improve the drought resistance of $P$. hunanensis.

Ashraf et al. [56] have shown that the dose effect of GB is related to the target plant species, the time and method of GB use, the site of plant application, the stage of plant growth, and the habitat of plant. Therefore, in the practical productions, we should determine the best method of GB application (e.g., soaking or spraying) for the target species and whether it is sprayed on the root system or the leaf surface. In addition, the optimal dosage, time, and frequency of GB application should be determined to maximize the role of GB as a stress resistance regulator, facilitate the normal growth of target species in adverse environments, and promote the commercial application of GB. Otherwise, its application may have a negative impact on the growth of crops and trees, causing unnecessary agricultural economic losses and ecological environment damage.

\section{Conclusion}

We investigated the physiological and biochemical responses of $P$. hunanensis to drought stress with exogenous GB application. Oxidative stress was dominant due to drought stress. However, the 
application of GB significantly increased the relative water content and osmotic adjustment substances and reduced oxidative stress by improving antioxidant enzymes under drought stress. The GB application also protected cell membrane permeability. The mechanism by which GB influences $P$. hunanensis under drought stress remains unclear. Hence, further studies are needed at the field level to understand to role and mechanisms of GB towards various plant species under drought stress.

Author's Contributions: Yongjun Fei and Zuguo Ge jointly conceived the study. Yujie Yang and Chengshi Huang performed and designed experiments, analyzed data, and wrote the manuscript. Bengeng Zhou, Guangju Su, and Chunling Liu helped with further experimentation and revisions to the manuscript. All authors read and approved the final version of the manuscript.

Funding Statement: This work was supported by the Science and Technology Research Project of Hubei Provincial Department of Education (Q20191309), the Engineering Research Center of Ecology and Agricultural Use of Wetland (Ministry of Education, KF2018113), and Shuangzhu Forest Farm in Zhuxi County $(2020 \mathrm{H} 21003)$.

Conflicts of Interest: The authors declare that they have no conflicts of interest to report regarding the present study.

\section{References}

1. Luo, L. J., Xia, H., Lu, B. R. (2019). Editorial: Crop breeding for drought resistance. Front Plant Science, 10, 314. DOI 10.3389/fpls.2019.00314.

2. Banks, J. M., Percival, G. C., Rose, G. (2019). Variations in seasonal drought tolerance rankings. Trees, 33(4), 1063-1072. DOI 10.1007/s00468-019-01842-5.

3. Fallahi, H. R., Taherpour, R., Aghhavani-Shajari, M., Soltanzadeh, M. G. (2015). Effect of super absorbent polymer and deficit irrigation on water use efficiency, growth and yield of cotton. Notulae Scientia Biologicae, 7(3), 338-344. DOI 10.15835/nsb739626.

4. Miri, M. R., Ghooshchi, F., Tohidi-Moghadam, H. R., Larijani, H. R., Kasraie, P. (2021). Ameliorative effects of foliar spray of glycine betaine and gibberellic acid on cowpea (Vigna unguiculata L. walp.) yield affected by drought stress. Arabian Journal of Geosciences, 14(10), 1-9. DOI 10.1007/s12517-021-07228-7.

5. Guo, Y. Y., Yu, H. Y., Yang, M. M., Kong, D. S., Zhang, Y. J. (2018). Effect of drought stress on lipid peroxidation, osmotic adjustment and antioxidant enzyme activity of leaves and roots of Lycium ruthenicum Murr. seedling. Russian Journal of Plant Physiology, 65(2), 244-250. DOI 10.1134/S1021443718020127.

6. Bulgari, R., Franzoni, G., Ferrante, A. (2019). Biostimulants application in horticultural crops under abiotic stress conditions. Agronomy, 9, 306. DOI 10.3390/agronomy9060306.

7. Drobek, M., Frac, M., Cybulska, J. (2019). Plant biostimulants: Importance of the quality and yield of horticultural crops and improvement of plant tolerance to abiotic stress-A review. Agronomy, 9, 335. DOI 10.3390/ agronomy9060335.

8. Ullah, N., Ditta, A., Khalid, A., Mehmood, S., Rizwan, M. S. et al. (2020). Integrated effect of algal biochar and plant growth-promoting rhizobacteria on physiology and growth of maize under deficit irrigations. Journal of Soil Science and Plant Nutrition, 20, 346-356. DOI 10.1007/s42729-019-00112-0.

9. Wani, S. H., Singh, N. B., Haribhushan, A., Mir, J. I. (2013). Compatible solute engineering in plants for abiotic stress tolerance-role of glycine betaine. Current Genomics, 14(3), 157-165. DOI 10.2174/1389202911314030001.

10. Tisarum, R., Theerawitaya, C., Samphumphuang, T., Singh, H. P., Chaum, S. (2020). Foliar application of glycinebetaine regulates soluble sugars and modulates physiological adaptations in sweet potato (Ipomoea batatas) under water deficit. Protoplasma, 257, 197-211. DOI 10.1007/s00709-019-01429-4.

11. Wang, N., Cao, F., Richmond, M. E. A., Qiu, C., Wu, F. (2019). Foliar application of betaine improves water-deficit stress tolerance in barley (Hordeum vulgare L.). Plant Growth Regulation, 89, 109-118. DOI 10.1007/s10725019-00510-5. 
12. Jabeen, N., Abbas, Z., Iqbal, M., Rizwan, M., Jabbar, A. et al. (2016). Glycine betaine mediates chromium tolerance in mung bean through lowering of $\mathrm{Cr}$ uptake and improved antioxidant system. Archives of Agronomy and Soil Science, 62, 648-662. DOI 10.1080/03650340.2015.1082032.

13. Rady, M. O. A., Semida, W. M., Abd El-Mageed, T. A., Hemida, K. A., Rady, M. M. (2018). Up-regulation of antioxidative defense systems by glycine betaine foliar application in onion plants confer tolerance to salinity stress. Science Horticulture, 240, 614-622. DOI 10.1016/j.scienta.2018.06.069.

14. Ahmad, R., Shafaqat, A., Muhammad, A., Muhammad, R., Basharat, A. et al. (2020). Glycinebetaine alleviates the chromium toxicity in Brassica oleracea L. by suppressing oxidative stress and modulating the plant morphology and photosynthetic attributes. Environmental Science and Pollution Research, 27, 1101-1111. DOI 10.1007/s11356-019-06761-z.

15. Li, X. H., Dong, Y. X., Xu, S. Q., Huang, B. (2009). Roles of birds in seed dispersal of Phoebe hunanensis in spirit valley forest of nanjing. Chinese Journal of Ecology, 28(1), 32-37. DOI 10.3321/j.issn:1002-008X.2001.05.010.

16. Zhang, J., Xu, S. Y., Li, G., Wang, Q., Fei, Y. J. (2016). Morphological characteristics of seeds in five species of phoebe and its taxonomic significance. Seed, 35(2), 50-53. DOI 10.16590/j.cnki.1001-4705.2016.02.050.

17. Wu, Q. S. (2018). Experimental guidelines in plant physiology. Beijing: China Agriculture Press.

18. Feng, G., Yang, H., Li, Y. (2005). Kinetics of relative electrical conductivity and correlation with gas composition in modified atmosphere packaged bayberries (Myrica rubra siebold and zuccarini). LWT-Food Science and Technology, 38(3), 249-254. DOI 10.1016/j.lwt.2004.05.015.

19. Zhao, D., Shen, L., Fan, B., Yu, M., Zheng, Y. et al. (2009). Ethylene and cold participate in the regulation of LeCBF1 gene expression in postharvest tomato fruits. FEBS Letters, 583(20), 3329-3334. DOI 10.1016/j. febslet.2009.09.029.

20. Li, Z., Peng, Y., Su, X. Y. (2013). Physiological responses of white clover by different leaf types associated with antioxidative enzyme protection and osmotic adjustment under drought stress. Acta Prataczulturae Sinica, 22(2), 257-263. DOI 10.1004-5759(2013)02-0257-07.

21. Riazi, A., Matsuda, K., Arslan, A. (1985). Water-stress induced changes in concentrations of proline and other solutes in growing regions of young barley leaves. Journal of Experimental Botany, 36, 1716-1725. DOI 10.1093/jxb/36.11.1716.

22. Bradford, M. M. (1976). A rapid and sensitive method for the quantification of microgram quantities of protein utilizing the principle of protein-dye binding. Analytical Biochemistry, 72, 248-254. DOI 10.1016/0003-2697 (76)90527-3.

23. Oberley, L. W., Spitz, D. R. (1984). Assay of superoxide dismutase activity in tumor tissue. Methods in Enzymology, 105, 457-464. DOI 10.1016/S0076-6879(84)05064-3.

24. Jung, W. J., Jin, Y. L., Kim, Y. C., Kim, K. Y., Park, R. D. et al. (2004). Inoculation of Paenibacillus illinoisensis alleviates root mortality, activates of lignification-related enzymes, and induction of the isozymes in pepper plants infected by phytophthora capsici. Biological Control, 30(3), 645-652. DOI 10.1016/j.biocontrol.2004.03.006.

25. Aebi, H. (1984). Catalase in vitro. In: Packer, L. (eds.) Methods in Enzymology, pp. 121-126. Amsterdam: Elsevier.

26. Yang, Y., Li, W., He, X., Hu, D., Fei, Y. (2020). Effects of lead on growth, osmotic adjustment, antioxidant activity and photosynthetic responses in Phoebe chekiangensis seedlings. Notulae Botanicae Horti Agrobotanici ClujNapoca, 48(3), 1637-1648. DOI 10.15835/nbha48311933.

27. Shemi, R., Wang, L., Zhang, K., Gheith, E. (2021). Effects of salicylic acid, zinc and glycine betaine on morphophysiological growth and yield of maize under drought stress. Scientific Reports, 11(1), 3195. DOI 10.1038/s41598-021-82264-7.

28. Genard, H., Le Saos, J., Billard, J. P., Tremolieres, A., Boucaud, J. (1991). Effect of salinity on lipid composition, glycine betaine content and photosynthetic activity in chloroplasts of Suaeda maritime. Plant Physiology and Biochemistry, 29, 421-427. DOI 10.1104/pp.97.1.472.

29. Alasvandyari, F., Mahdavi, B., Hosseini, S. M. (2017). Glycine betaine affects the antioxidant system and ion accumulation and reduces salinity-induced damage in safflower seedlings. Archives of Biological Sciences, 69(1), 139-147. DOI 10.2298/ABS160216089A. 
30. Nawaz, M., Wang, Z. (2020). Abscisic acid and glycine betaine mediated tolerance mechanisms under drought stress and recovery in Axonopus compressus: A new insight. Scientific Reports, 10(1), 6942. DOI 10.1038/ s41598-020-63447-0.

31. Nazar, Z., Akram, N. A., Saleem, M. H., Ashraf, M., Ahmed, S. et al. (2020). Glycinebetaine-induced alteration in gaseous exchange capacity and osmoprotective phenomena in safflower (Carthamus tinctorius L.) under water deficit conditions. Sustainability, 12(24), 10649. DOI 10.3390/su122410649.

32. Ozturk, M., Unal, B. T., García-Caparrós, P., Khursheed, A., Hasanuzzaman, M. (2021). Osmoregulation and its actions during the drought stress inplants. Physiologia Plantarum, 172(2), 1321-1335. DOI 10.1111/ppl.13297.

33. Zegaoui, Z., Planchais, S., Cabassa, C., Djebbar, R., Belbachir, O. A. et al. (2017). Variation in relative water content, proline accumulation and stress gene expression in two cowpea landraces under drought. Journal of Plant Physiology, 218, 26-34. DOI 10.1016/j.jplph.2017.07.009.

34. Nemati, M., Piro, A., Norouzi, M., Vahed, M. M., Nisticò, D. M. et al. (2019). Comparative physiological and leaf proteomic ana-lyses revealed the tolerant and sensitive traits to drought stress in twowheat parental lines and their F6 progenies. Environmental and Experimental Botany, 158, 223-237. DOI 10.1016/j.envexpbot.2018.10.024.

35. Gupta, N., Thind, S. K. (2019). Foliar application of glycine betaine alters sugar metabolism of wheat leaves under prolonged field drought stress. Proceedings of the National Academy of Sciences, India Section B: Biological Sciences, 89, 877-884. DOI 10.1007/s40011-018-1000-2.

36. Mattioni, C., Lacerenza, N. G., Troccoli, A., Leonardis, A. M. D., Fonzo, N. D. (1997). Water and salt stressinduced alternations in proline metabolism of tritucum durum seedlings. Physiologia Plantarum, 101, 787-792. DOI 10.1111/j.1399-3054.1997.tb01064.x.

37. Wang, L. P. (2015). Drought-resisitance for five dwarfing interstocks and effects of glycinebetaine on droughtresistance of apple sapling (Master Dissertation), Shandong Agricultural University.

38. Li, Q., Zhang, X., Lv, Q., Zhu, D., Qiu, T. et al. (2017). Physcomitrella patens dehydrins (PpDHNA and PpDHNC) confer salinity and drought tolerance to transgenic arabidopsis plants. Front Plant Science, 8, 1316. DOI 10.3389/ fpls.2017.01316.

39. Raza, M. A. S., Saleem, M. F., Shah, G. M., Khan, I. H., Raza, A. (2014). Exogenous application of glycinebetaine and potassium for improving water relations and grain yield of wheat under drought. Journal of Soil Science and Plant Nutrition, 14, 348-364. DOI 10.4067/S0718-95162014005000028.

40. Bourot, S., Sire, O., Trautwetter, A., Touze, T., Bernard, T. (2000). Glycine betaine-assisted protein folding in alysA mutant of escherichia coli. Journal of Biological Chemistry, 275(2), 1050-1056. DOI 10.1074/ jbc.275.2.1050.

41. Iqbal, N., Ashraf, Y., Ashraf, M. (2011). Modulation of endogenous levels of some key organic metabolites by exogenous application of glycine betaine in drought stressed plants of sunflower (Helianthus annuus L.). Plant Growth Regulation, 63(1), 7-12. DOI 10.1007/s10725-010-9506-5.

42. Hussain, H. A., Men, S., Hussain, S., Zhang, Q., Ashraf, U. et al. (2020). Maize tolerance against drought and chilling stresses varied with root morphology and antioxidative defense system. Plants, 9(6), 720. DOI 10.3390/plants9060720.

43. Jia, X. J., Dong, L. H., Ding, C. B., Li, X., Yuan, M. (2013). Effects of drought stress on reactive oxygen species and their scavenging systems in Chlorophytum capense var. medio-pictumleaf. Acta Prataculturae Sinica, 22(5), 248-255. DOI 10.1004-5759(2013)05-0248-08.

44. Bami, S. S., Khavari-Nejad, R. A., Ahadi, A. M., Rezayatmand, Z. (2021). Tio 2 nanoparticles effects on morphology and physiology of Artemisia absinthium L. under salinity stress. Iranian Journal of Science and Technology, Transactions A: Science, 45(1), 27-40. DOI 10.1007/s40995-020-00999-w.

45. Bouslimi, H., Ferreira, R., Dridi, N., Brito, P., Sleimi, N. (2021). Effects of barium stress in Brassica juncea and Cakile maritima: The indicator role of some antioxidant enzymes and secondary metabolites. Phyton-International Journal of Experimental Botany, 90(1), 145-158. DOI 10.32604/phyton.2020.011752.

46. Wei, D., Zhang, W., Wang, C., Meng, Q., Li, G. et al. (2017). Genetic engineering of the biosynthesis of glycinebetaine leads to alleviate salt-induced potassium efflux and enhances salt tolerance in tomato plants. Plant Science, 257, 74-83. DOI 10.1016/j.plantsci.2017.01.012. 
47. Denaxa, N. K., Damvakaris, T., Roussos, P. A. (2020). Antioxidant defense system in young olive plants against drought stress and mitigation of adverse effects through external application of alleviating products. Scientia Horticulturae, 259, 108812. DOI 10.1016/j.scienta.2019.108812.

48. Yadu, B., Chandrakar, V., Meena, R. K., Keshavkant, S. (2017). Glycinebetaine reduces oxidative injury and enhances fluoride stress tolerance via improving antioxidant enzymes, proline and genomic template stability in Cajanus cajan L. South African Journal of Botany, 111, 68-75. DOI 10.1016/j.sajb.2017.03.023.

49. Sofy, M. R., Elhawat, N., Alshaal, T. (2020). Glycine betaine counters salinity stress by maintaining high $\mathrm{K}^{+} / \mathrm{Na}^{+}$ ratio and antioxidant defense via limiting $\mathrm{Na}^{+}$uptake in common bean (Phaseolus vulgaris L.). Ecotoxicology and Environmental Safety, 200(9), 110732. DOI 10.1016/j.ecoenv.2020.110732.

50. Liaqat, S., Masroor, A., Ghafoor, F., Maqsood, Z., Ghafoor, A. (2020). Effect of glycine betaine as a growth promoter and stress mitigator in Brassica oleraceavar. Italica. Journal La Lifesci, 1(4), 31-35. DOI 10.37899/ journallalifesci.v1i4.206.

51. Uosukainen, M., Rantala, S., Manninen, A., Vestberg, M. (2000). Improvement of microplant establishment through in vitro and ex vitro exogenous chemical applications. Acta Horticulturae, 10(530), 325-331. DOI 10.17660/ActaHortic.2000.530.38.

52. Tisarum, R., Theerawitaya, C., Samphumphung, T., Takabe, T., Cha-Um, S. (2019). Exogenous foliar application of glycine betaine to alleviate water deficit tolerance in two indica rice genotypes under greenhouse conditions. Agronomy, 9(3), 138. DOI 10.3390/agronomy9030138.

53. Naidu, B. P., Cameron, D. F., Konduri, S. V. (1998). Improving stress tolerance and productivity of plants by a biochemical approach in agronomy and plant breeding. Proceeding of the $1 X$ Australian Agronomy Conference, pp. 355-358, Wagga, Australia.

54. He, L. D., Liu, G. M., Yang, J. S., Li, J. B., Lv, Z. Z. (2013). Mitigative of glycinebetaine on salt stress of Lolium perenne seedlings. Acta Pedologica Sinica, 50(5), 1055-1060. DOI 10.11766/trxb201301220044.

55. Hu, L., Hu, T., Zhang, X., Pang, H., Fu, J. (2012). Exogenous glycine betaine ameliorates the adverse effect of salt stress on perennial ryegrass. Journal of the American Society for Horticultural Science, 137(1), 38-46. DOI 10.21273/JASHS.137.1.38.

56. Ashraf, M., Foolad, M. (2007). Roles of glycine betaine and proline in improving plant abiotic stress resistance. Environmental and Experimental Botany, 59(2), 206-216. DOI 10.1016/j.envexpbot.2005.12.006. 


\section{Appendix}

Table S1: Physiological effect of $P$. hunanensis under drought stress

\begin{tabular}{|c|c|c|c|c|c|c|c|}
\hline \multirow[t]{2}{*}{ Physiological index } & \multirow{2}{*}{$\begin{array}{l}\text { Irrigation } \\
\text { conditions }(\mathrm{mL})\end{array}$} & \multicolumn{6}{|c|}{ Days of treatment } \\
\hline & & 0 & 5 & 10 & 15 & 20 & 25 \\
\hline \multirow{2}{*}{$\begin{array}{l}\text { Relative water } \\
\text { content }(\%)\end{array}$} & 0 & $80.22 \pm 0.57$ & $75.11 \pm 1.52$ & $68.08 \pm 1.44$ & $57.02 \pm 1.22$ & $41.12 \pm 2.65$ & $35.45 \pm 3.12$ \\
\hline & 800 & $84.37 \pm 2.35$ & $85.31 \pm 2.42$ & $84.36 \pm 2.94$ & $83.41 \pm 1.78$ & $85.95 \pm 2.92$ & $85.51 \pm 3.26$ \\
\hline \multirow[t]{2}{*}{ Electric conductivity $(\%)$} & 0 & $20.37 \pm 0.78$ & $23.03 \pm 1.01$ & $28.37 \pm 0.19$ & $34.04 \pm 1.07$ & $40.75 \pm 0.62$ & $43.63 \pm 1.44$ \\
\hline & 800 & $23.81 \pm 0.72$ & $24.56 \pm 1.21$ & $26.45 \pm 1.51$ & $25.58 \pm 0.38$ & $26.48 \pm 0.65$ & $26.79 \pm 0.84$ \\
\hline \multirow[t]{2}{*}{$\operatorname{MDA}\left(\mathrm{nmol} \cdot \mathrm{g}^{-1}\right)$} & 0 & $7.37 \pm 0.23$ & $7.74 \pm 0.35$ & $10.25 \pm 0.42$ & $14.94 \pm 0.56$ & $16.48 \pm 0.73$ & $19.47 \pm 0.84$ \\
\hline & 800 & $7.21 \pm 0.19$ & $6.72 \pm 0.22$ & $7.85 \pm 0.57$ & $10.65 \pm 0.31$ & $14.75 \pm 0.36$ & $13.67 \pm 0.57$ \\
\hline \multirow[t]{2}{*}{ Proline $\left(\mathrm{mg} \cdot \mathrm{g}^{-1}\right)$} & 0 & $0.14 \pm 0.04$ & $0.23 \pm 0.01$ & $0.45 \pm 0.10$ & $0.44 \pm 0.09$ & $0.64 \pm 0.12$ & $0.86 \pm 0.08$ \\
\hline & 800 & $0.18 \pm 0.02$ & $0.19 \pm 0.02$ & $0.32 \pm 0.01$ & $0.41 \pm 0.06$ & $0.42 \pm 0.11$ & $0.46 \pm 0.21$ \\
\hline \multirow[t]{2}{*}{ Soluble protein $\left(\mathrm{mg} \cdot \mathrm{g}^{-1}\right)$} & 0 & $2.00 \pm 0.10$ & $2.11 \pm 0.04$ & $2.23 \pm 0.15$ & $2.42 \pm 0.02$ & $2.61 \pm 0.07$ & $2.80 \pm 0.19$ \\
\hline & 800 & $1.84 \pm 0.21$ & $2.10 \pm 0.12$ & $2.01 \pm 0.09$ & $2.15 \pm 0.05$ & $2.26 \pm 0.21$ & $2.35 \pm 0.12$ \\
\hline \multirow[t]{2}{*}{ Soluble sugars $(\%)$} & 0 & $0.38 \pm 0.01$ & $0.42 \pm 0.01$ & $0.46 \pm 0.02$ & $0.48 \pm 0.01$ & $0.54 \pm 0.02$ & $0.61 \pm 0.02$ \\
\hline & 800 & $0.37 \pm 0.01$ & $0.55 \pm 0.21$ & $0.42 \pm 0.01$ & $0.42 \pm 0.01$ & $0.42 \pm 0.01$ & $0.38 \pm 0.04$ \\
\hline \multirow[t]{2}{*}{$\operatorname{SOD}\left(\mathrm{U} \cdot \mathrm{g}^{-1} \cdot \min ^{-1}\right)$} & 0 & $15.56 \pm 2.15$ & $17.54 \pm 1.01$ & $19.58 \pm 0.72$ & $24.45 \pm 1.44$ & $29.32 \pm 1.07$ & $30.89 \pm 0.62$ \\
\hline & 800 & $13.42 \pm 1.36$ & $16.43 \pm 1.32$ & $18.56 \pm 0.38$ & $19.35 \pm 0.18$ & $17.89 \pm 0.97$ & $18.35 \pm 1.52$ \\
\hline \multirow[t]{2}{*}{$\operatorname{CAT}\left(\mathrm{U} \cdot \mathrm{g}^{-1} \cdot \mathrm{min}^{-1}\right)$} & 0 & $0.28 \pm 0.05$ & $0.37 \pm 0.01$ & $0.48 \pm 0.02$ & $0.54 \pm 0.05$ & $0.63 \pm 0.01$ & $0.79 \pm 0.03$ \\
\hline & 800 & $0.35 \pm 0.12$ & $0.31 \pm 0.02$ & $0.42 \pm 0.04$ & $0.39 \pm 0.04$ & $0.41 \pm 0.02$ & $0.46 \pm 0.04$ \\
\hline \multirow[t]{2}{*}{$\operatorname{POD}\left(\mathrm{U} \cdot \mathrm{g}^{-1} \cdot \mathrm{min}^{-1}\right)$} & 0 & $1004 \pm 4.35$ & $1100 \pm 14.55$ & $1345 \pm 12.97$ & $1770 \pm 19.42$ & $2148 \pm 22.86$ & $2638 \pm 21.32$ \\
\hline & 800 & $1001 \pm 2.51$ & $1108 \pm 12.32$ & $1347 \pm 11.75$ & $1225 \pm 15.43$ & $1463 \pm 10.50$ & $1435 \pm 25.68$ \\
\hline
\end{tabular}

